\title{
Zebrafish as an experimental model for the simulation of neurological and craniofacial disorders
}

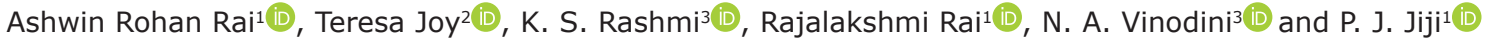 \\ 1. Department of Anatomy, Kasturba Medical College, Mangalore, Manipal Academy of Higher Education, Manipal, \\ Karnataka, India; 2. Department of Anatomy, American University of Antigua College of Medicine, University Park \\ Coolidge, St. John's, Antigua; 3. Department of Physiology, Kasturba Medical College, Mangalore, Manipal Academy of \\ Higher Education, Manipal, Karnataka, India. \\ Corresponding author: Teresa Joy, e-mail: tjoy@auamed.net \\ Co-authors: ARR: ashwin.rai@manipal.edu, KSR: rashmi.ks@manipal.edu, RR: rajalakshmi.rai@manipal.edu, \\ NAV: vinodini.na@manipal.edu, PJJ: jiji.pj@manipal.edu \\ Received: 02-08-2021, Accepted: 30-11-2021, Published online: 11-01-2022
}

doi: www.doi.org/10.14202/vetworld.2022.22-29 How to cite this article: Rai AR, Joy T, Rashmi KS, Rai R, Vinodini NA, Jiji PJ (2022) Zebrafish as an Experimental Model for the Simulation of Neurological and Craniofacial Disorders, Veterinary World, 15(1): 22-29.

\begin{abstract}
Zebrafish have gained momentum as a leading experimental model in recent years. At present, the zebrafish vertebrate model is increasingly used due to its multifactorial similarities to humans that include genetic, organ, and cellular factors. With the emergence of novel research techniques that are very expensive, it is necessary to develop affordable and valid experimental models. This review aimed to highlight some of the most important similarities between zebrafish and humans by emphasizing the relevance of the first in simulating neurological disorders and craniofacial deformity.
\end{abstract}

Keywords: craniofacial deformity, experimental model, neurological disorders, zebrafish.

\section{Introduction}

The zebrafish (Danio rerio; ZF) are freshwater fish belonging to the minnow tribe of the Cypriniformes order. It is a tropical fish native to Southeast Asia that is about 2.5-4 cm long. It is a popular aquarium fish, and it is easily available and cheap. ZF have the advantage of being able to tolerate water of low ion content [1,2]. They are shallow water habitants found in shallow ponds, canals, and streams, preferably in stagnant waters or slow flowing waters with a temperature between $6^{\circ} \mathrm{C}$ and $38^{\circ} \mathrm{C}$ [3]; hence, they can be well maintained in aquaria made of high-quality plastic and glass [4]. The capacity of the tank is determined as per the number of fish housed. A maximum of 10-12 ZF can be accommodated in 10 gal. of water. Soft water is ideal [5] for the housing of $\mathrm{ZF}$, particularly when a $\mathrm{pH}$ of 7 is maintained [6]. $\mathrm{ZF}$ (being an omnivorous species) feed on animal and plant matter such as zooplankton, insects, algae, fish scales, sand, mud, and invertebrate eggs [7]. The laboratory $\mathrm{ZF}$ are fed with a commercially available tropical fish diet [8]. The sexual dimorphism in ZF is difficult to assess, but they can be distinguished by their body shape and color. Male ZF are more slender and display a golden red shade between their blue stripes, whereas female ZF exhibit a protruding belly,

Copyright: Rai, et al. Open Access. This article is distributed under the terms of the Creative Commons Attribution 4.0 International License (http://creativecommons.org/licenses/by/4.0/), which permits unrestricted use, distribution, and reproduction in any medium, provided you give appropriate credit to the original author(s) and the source, provide a link to the Creative Commons license, and indicate if changes were made. The Creative Commons Public Domain Dedication waiver (http://creativecommons.org/ publicdomain/zero/1.0/) applies to the data made available in this article, unless otherwise stated. with their body having alternate blue stripes with silver stripes [9]. ZF undergo external fertilization and embryo development that produces a great number of progeny [10]. The optimal temperature for embryo production and breeding depends on the advent of light, on a 14:10 h light and dark cycle, on maintaining water temperature between $23^{\circ} \mathrm{C}$ and $28^{\circ} \mathrm{C}$, and on maintaining water $\mathrm{pH}$ between 6.2 and 7.5 [11]. The mating processes involve three phases (namely, initiatory, receptive, and spawning phase) [12]. The female ZF release hundreds of eggs in a clutch at a time into the water [13]. They are highly fertile and lay offspring at quite an early age. The sexual maturity of the laboratory ZF is attained by the $3^{\text {rd }}$ month of their development, whereas their ideal reproductive age lies between 6 months and 1 year, while their lifespan can reach up to 5 years [9]. From the $3^{\text {rd }}$ day of fertilization, $\mathrm{ZF}$ are eligible for larval experiments. In fact, the ZF teleost lives in conditions that can be easily replicated ex situ.

ZF are used by many laboratories to substitute and/or to supplement higher vertebrate models due to their similarities regarding many features of their embryonic development and adult anatomy with those of humans [14,15]. Their relatively small size and radiant feature allow for the observation of the entire animal [16]; hence, ZF are an excellent animal model for learning the different pathophysiological processes in organogenesis, embryogenesis, and carcinogenesis as well as for undertaking pharmacological and toxicological studies [17-19]. Their egg size is small, and their translucent embryos make experimental manipulations such as cell labeling, lineage tracing, and cell transplantation significantly smoother. Unlike higher organisms, the ZF organ system is highly minimalistic 
[10]. The ZF model has benefited from the advances in genetics, as ZF tumor cell lines of any kind have been established by inducing the related gene expression and being able to effectively simulate cancer morphology and signaling pathways [20,21]. ZF models enable faster and relevant in vivo screening through imaging of the pathogenesis, thus providing critical insights into the molecular mechanisms of the disease $[22,23]$. The fully mapped ZF genome has revealed extensive homology with the human genome, thus making ZF an excellent tool for studying human pathologies [24]. In fact, $\mathrm{ZF}$ exhibit $70 \%$ gene homology with humans, while $84 \%$ of the genes identified in human diseases are also expressed in this teleost species [25].

The currently available animal models can simulate most of the cognitive and molecular aspects of human pathologies, but they are time constraint and expensive; in contrast, the ZF model is an efficient, robust, and unique drug screening tool [26]. Moreover, the $\mathrm{ZF}$ ventral telencephalon is homologous to the human striatum [27]. The ZF immune system is functionally developed within $48 \mathrm{~h}$ post-fertilization and, in a similar extent to that of mammals, it has neutrophils, natural killer cells, monocytes/macrophages, and non-specific cytotoxic cells [28]. There is continuous tooth regeneration in $\mathrm{ZF}$, providing us with the opportunity to better understand tooth replacement in mammals. Even if they are more favorable as models than rodents in many research areas, ZF lacks skin, mammary glands, lungs, and prostate organs. However, like vertebrates, ZF have organs and tissues that show equivalent morphology and function to humans (heart, kidney, liver, pancreas, gastrointestinal tract, and brain) [24]. Studies have also reported that the sleep pattern in the brain of ZF is similar to that of sleeping humans, which involve rapid eye movement (REM) and non-REM sleep [29]. Jeong et al. [30] have revealed that the endothelial tight junction-based blood-brain barrier (BBB) of ZF is similar to that of humans. This BBB and blood-retinal barrier develop in ZF embryos by 3 days post-infection on a transgenic ZF model has been revealed [31]. This review focuses on $\mathrm{ZF}$ as a novel model for studying neurodegenerative diseases and craniofacial development.

\section{ZF as Model for the Experimental Simulation of Neurological Disorders}

The sequencing of the entire ZF genome has revealed that $70 \%$ of the proteins encoded by human genes are related to genes found in ZF, while 84\% of the ZF genes are known to be associated with human diseases [32]. The nervous system of the ZF is simple, with individual elements (glutamatergic excitatory neurons and GABAergic inhibitory neurons) [33]. Decui et al. [34] have recently presented data that reveal that micronized resveratrol can prevent pentylenetetrazole (PTZ)-induced seizure in epilepsy, whereas results by Mazumder et al. [35] have suggested that the anticonvulsant action of the phosphatidylinositol-3-kinase inhibitor LY294002 can be highly potential against PTZ-induced convulsions. Choo et al. [36] have reported that newer antiepileptic drugs can trigger cognitive deficits in a PTZ-induced ZF model of epilepsy. It has been demonstrated that Orthosiphon stamineus, a leaf extract, has anticonvulsant properties and can affect the levels of tumor necrosis factor-alpha (TNF- $\alpha)$ and the occurrence of seizures in a ZF model of epilepsy [37]. Li et al. [38] have evaluated the hazardous effects of nano-silica and reserpine on ZF, claiming that both can cause depression, anxiety-like behavior, disturbed swimming, and exploratory behavior, along with reduced locomotion and a depressive phenotype. Furthermore, Li et al. [39] have assessed the neurotoxic effects of silica nanoparticles as a potential source of neurobehavioral toxicity in Parkinson's disease (PD). On the other hand, Cronin and Grealy have developed a ZF model to screen drugs with potential neuroprotective and neurorestorative effects against PD [40]. Flinn et al, [41] have created a ZF model to investigate the mechanisms underlying neuronal cell death in early onset PD. Exposure to neurotoxins has been shown to cause a decrease in dopamine levels in ZF, thus making it an ideal teleost for the simulation and study of neuropsychiatric diseases, as underlined by Panula et al. [42].

Piato et al. [43] have developed a ZF model allowing the study of the effects of chronic stress (lasting 7-14 days) through the assessment of psychological and behavioral responses. Similarly, Chakravarty et al. [44] have managed to induce anxiety and mood-related disorders through the application of unpredictable chronic stress in ZF, and observed decreased neurogenesis complicated by mitochondrial dysfunction. Rambo et al. [45] have demonstrated that unpredictable chronic stress can increase locomotion in female ZF, whereas male ZF exhibited higher cortisol levels along with increased aggressive behavior. Demin et al. [46] demonstrated that the ZF tail immobilization test can act as an appropriate tool for the assessment of stress. According to Wei et al. [47], long-term exposure to bisphenol $\mathrm{S}$ can lead to stress and anxiety-like behavior in ZF. These symptoms were shown to be alleviated by tryptophan and fluoxetine treatment in a study undertaken by Giacomini et al. [48]. Sarasamma et al. [49] were able to demonstrate that exposure to zinc chloride can induce an impaired short-term memory and diminished locomotion that mimicked Alzheimer's disease (AD), along with an induction of beta-amyloid ( $\beta$-amyloid) and tau protein in the ZF brain. Koehler and Williams [26] have conducted a similar study in which a ZF AD model was generated using a protein phosphatase $2 \mathrm{~A}$ inhibitor (okadaic acid); in their study, a treatment with lanthionine ketimine-5-ethyl ester has shown neuroprotective effects [26]. Moreover, Javed et al. [50] have demonstrated the potency of casein-coated gold nanoparticles in reversing the cognitive and locomotor dysfunction 
of $\mathrm{ZF}$ exposed to the toxicity of $\beta$-amyloid in AD. Richetti et al. [51] have previously reported the potential protective effect of quercetin and rutin against scopolamine-induced memory impairment in a ZF AD model, whereas Yendapalli et al. [52] have evaluated the dual effects of Brassica juncea and Cynodon dactylon extracts on the cognitive performance of scopolamine-induced amnesic ZF.

Pullaguri et al. [53] have recently found that triclosan (an antimicrobial agent) can induce anxiety-like behavior in ZF; this behavior was linked to altered acetylcholinesterase (AChE) activity in the ZF brain and skeletal muscle, in addition to an observed downregulation of structural protein in the skeletal muscle. Nema and Bhargava [54] have reported that the ZF exhibit a frequent freezing behavior after exposure to cypermethrin (a pesticide) with no variations in their brain superoxide dismutase and AChE activities. Nery et al. [55] have injected $\beta$-amyloid 1-42 into the hindbrain ventricle of ZF embryos, resulting in increased tau phosphorylation and impaired cognition that were reversed by lithium. Prolonged exposure to low doses of benzo(a)pyrene (an environmental hazard) has been reported to lead to the development of neurodegenerative diseases (such as PD and AD) in ZF [56], along with locomotor dysfunction [57]. Prenatal exposure to the water-soluble fraction of crude oil and lead has been shown to cause autism-like behavioral deficits in ZF larvae [58].

Moreover, when ZF larvae were exposed to valproic acid, they developed autism spectrum-like symptoms $[59,60]$. It can be safely argued that $\mathrm{ZF}$ are an ideal model for the simulation of deficits that are relevant to autism [61]. A study conducted by Gawel et al. [62] have proved that ZF should also be considered an emerging model for schizophrenia [62]. Finally, using ZF as a model, Barnhill et al. [63] have provided new insights into the pathogenesis of PD that can also be extended into mammalian models [63].

The number of ZF utilizing neuroscientific studies is increasing exponentially, and it is much exceeding that of rodents or other model species. Despite this, there is still much resistance regarding using ZF as a primary experimental model system. New potential for understanding the pathobiology of diverse central nervous system (CNS) impairments continues to emerge from studies focusing on the array of the ZFneuronal and behavioral capabilities. Although some of these models (such as those for anxiety, depression, and addiction) are well established in ZF, others (such as those for autism and obsessive-compulsive disorders) are not as well established. However, accumulating evidence suggests that a wide range of CNS disorders could be reliably simulated with the use of ZF [64].

Another common misunderstanding is that the ZF are exclusively useful for the undertaking of genetic and developmental studies. The expanding applicability of ZF models in practically every aspect of biomedicine, including the modeling of brain diseases [65-67], supports the opposite, as evidenced by the mounting evidence provided herein. Similarly, research using larval ZF has dominated the field for decades. This scenario has only recently begun to improve, as more and more laboratories recognize the significance of adult ZF models for studying brain illnesses that mimic human pathologies [65].

\section{ZF as a Model for the Study of Craniofacial Development}

The ZF are a promising model for studying both the genetic and the environmental interactions occurring in craniofacial malformations such as palatal clefts. Over the last decade, the number of ZF genetic models for human disease-causing genes, such as those causing the cleft lip/palate, has exploded $[68,69]$. The ZF are a common model for visualizing the growth of the skull vault and of the cranial sutures. Kanther et al. [70] have hypothesized that the frontal and parietal bones of the skull meet and initiate suture formation after 30 days of development. Thyroid hormones are known to play an important role in the morphogenesis and ossification of the entire skeleton of ZF, according to a report by Keer et al. [71]. Like that of humans, the craniofacial mesenchyme is made up of migratory neural crest cells and paraxial mesoderm (Figure-1) [72]. The palatoquadrate and the posterior end of Meckel's cage are evolutionarily related to the malleus and the incus of the mammalian middle ear. In ZF, the hyomandibula is the counterpart of the mammalian stapes (inner ear). The attachment of the stapes to the oval window in the otic capsule in humans is represented by the relationship between the hyomandibula and the otic cartilage in ZF. The ZF neurocranium anterior end is similar to the mammalian hard palate (Figures-2 and 3) [73]. The specialized diphyodont and heterodont dentition of humans has derived from the polyphyodonty homodont dentition of teleosts [15]. The ZF dentition has a rich vasculature for the processing of tooth development and replacement [74]. Based on these similarities, researchers have used $\mathrm{ZF}$ to investigate the phenotypic variability of human birth defects. A ZF study has found that combined exposure to platelet-derived growth factor receptor alpha and ethanol can cause craniofacial defects similar to those observed in fetal alcohol spectrum disorders (FASDs) [75]. According to a review conducted by Ellis et al. [76], exposure to the total particular matter (TPM) of cigarette smoke

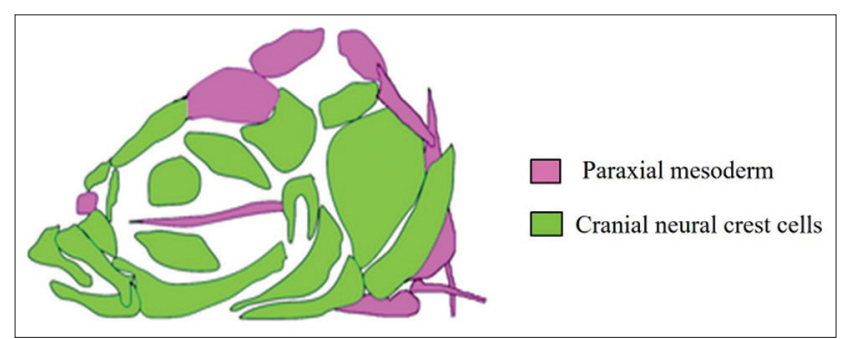

Figure-1: Craniofacial mesenchyme [72] 


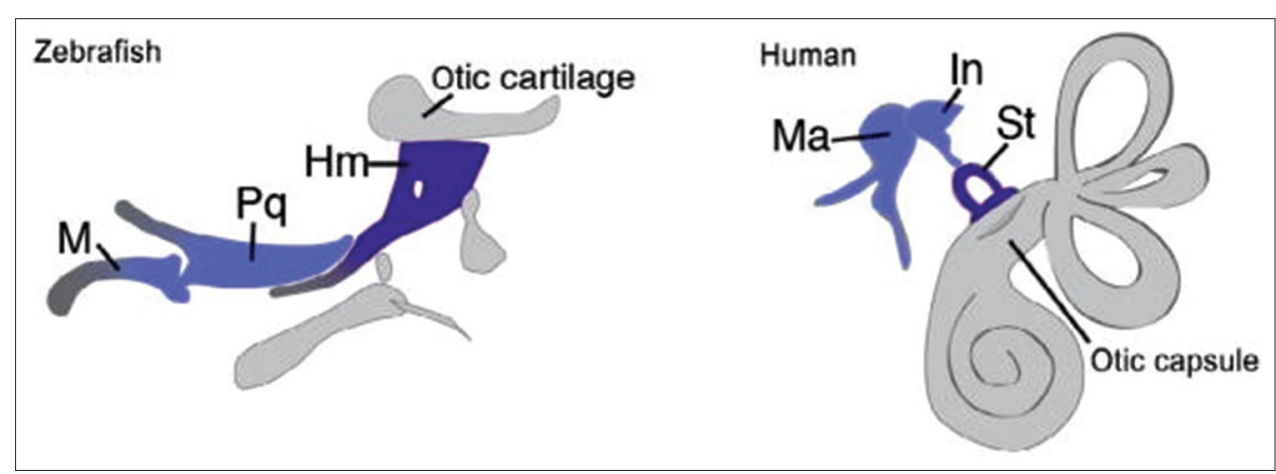

Figure-2: Zebrafish jaw homologous to mammalian middle ear [73].

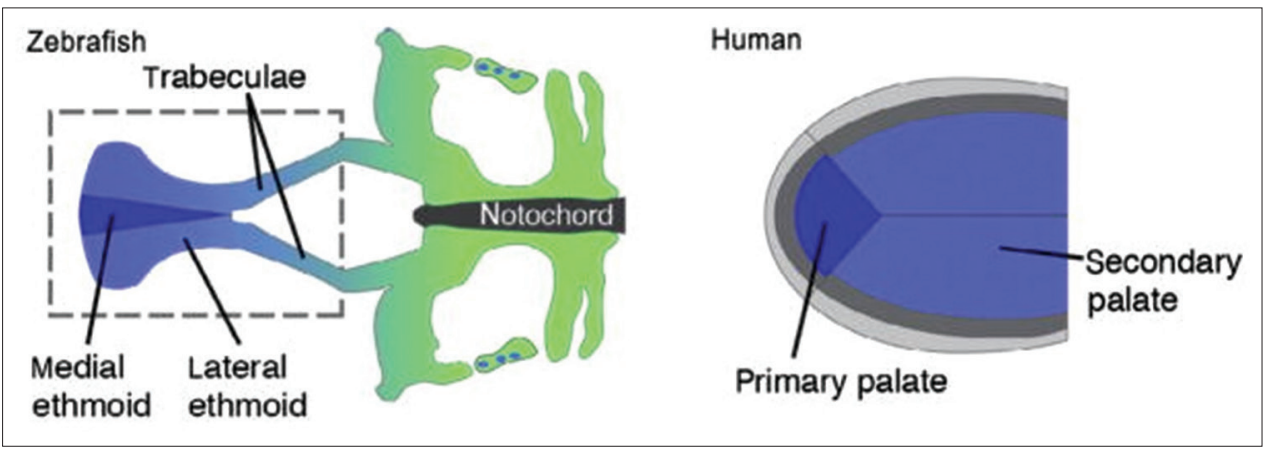

Figure-3: Zebrafish anterior neurocranium homologous to mammalian palate [73].

can induce craniofacial malformations in $\mathrm{ZF}$ when the TPM is $>6 \mathrm{~g} / \mathrm{mL}$. Moreover, exposure to TPM has been shown to increase larval motility, to cause gross morphological deformities, and to distort the AhR pathway-associated enzyme activity. TPM toxicity is known to be influenced in part by genetic factors that regulate xenobiotic metabolism [76-78]. The Wnt/ $\beta$ catenin signaling is a major pathway for craniofacial growth $[79,80]$. ZF exposed to alcohol during early gastrulation and neurulation have developed FASD symptoms that comprised differential expression of the sonic hedgehog pathway genes and the development of craniofacial malformations [81]. When ZF larvae were exposed to $100 \mathrm{mM}(2.4 \%)$ of ethanol, they presented with a reduced ethmoid plate width that was then rescued by a low dose $(1 \mathrm{nM})$ administration of exogenous retinoic acid (RA); moreover, when the RA was administered without a previous exposure of the ZF larvae to alcohol, the ZF developed a broader ethmoid plate [82].

A study conducted by Liu and Semina [83] who have demonstrated that a Paired-like homeodomain 2 transcription pathway deficiency can lead to abnormal ocular and craniofacial development. Treacher Collins syndrome, CHARGE syndrome [coloboma, heart defects, atresia choanae (also known as choanal atresia), growth retardation, genital abnormalities, and ear abnormalities], and Roberts syndrome have all been effectively standardized and can be simulated in ZF. These disorders comprise of cleft palate, microcephaly, smooth philtrum, and other malformities $[75,84]$. Exposure to dibutyl phthalate can induce defects in embryonic craniofacial development as reported by Jergensen et al. [85], whereas Cedron et. $a l$. [86] has suggested that the overuse of acetaminophen or paracetamol can lead to the development of morphological abnormalities in craniofacialstructures. Chiquet et al. [87] have used ZF as a powerful tool for studying orofacial abnormalities, including that of the cleft lip/cleft palate. Küchler et al. [88] have used $\mathrm{ZF}$ embryos to assess the link between hypoxia and oral clefts. Cranial deformity accompanied by oxidative stress was observed in ZF embryos exposed to boscalid (a fungicide) in a study conducted by Wang et al. [89]. A study has been conducted to examine the effect of hormones on craniofacial malformations on ZF larvae; During early chondrogenesis (1-2 dpf), ZF larvae exposed to exogenous $17 \beta$-estradiol (E2) have been shown to exhibit dose- and developmental stage-dependent craniofacial malformations with enhanced sensitivity [90]. With a focus on dental applicability, Makkar et al. [91] have studied the in vivo molecular toxicity profile of dental materials such as the mineral trioxide aggregate and biodentine using ZF models, whereas Rajendran et al. [92] have shown that zirconium oxide is more toxic to embryonic ZF even at low concentrations. The teeth in ZF larvae were treated with fluorine to examine them and compare the prevalence of dental fluorosis in primary and permanent teeth [93]. In an attempt to assess the protective effects of these products, Zhao et al. [94] have studied the impact of different metal alloy shells of Procelian fused metal alloy crowns on the growth of ZF embryos and larvae. Bisphenols have recently been the subject of a variety of ZF studies. For example, bisphenol $\mathrm{A}$ is an estrogen-like environmental 
compound that disrupts chondrocyte organization in the pharyngeal structures and induces apoptosis in $\mathrm{ZF}$ larvae, thus causing craniofacial malformations [95]. ZF are an excellent translational model for a wide range of craniofacial malformations, as well as for the assessment of the mechanisms of action associated with environmental pollutants and gene-environment interactions.

\section{Conclusion}

A significant amount of craniofacial growth and neurodegenerative research has used the $\mathrm{ZF}$ as a model. The findings of these experiments have been included in this review as a proof of the value of $\mathrm{ZF}$ as an experimental setup that is cost-effective and easy to handle. Furthermore, the study of ZF will be particularly useful in the discovery and risk assessment of new teratogens and assisting in the translation of preclinical data into practice, thus informing our health advice to expecting mothers to reduce the risk of craniofacial malformations and developing neurological disorders. The latter should encourage new research to be conducted on the ZF model with the hope that it will prove beneficial for the human race.

\section{Authors' Contributions}

ARR and TJ: Contributed to the original draft, investigation, and editing of the manuscript. KSR and NAV: Collected the relevant literature and edited the manuscript. RR and PJJ: Revised the manuscript. All authors have read and approved the final manuscript.

\section{Acknowledgment}

The authors are thankful to Manipal Academy of Higher Education, Kasturba Medical College, Mangalore, Karnataka, India. The authors did not receive any funds for this study.

\section{Competing Interests} interests.

The authors declare that they have no competing

\section{Publisher's Note}

Veterinary World remains neutral with regard to jurisdictional claims in published institutional affiliation.

\section{References}

1. Boisen, A.M.Z., Amstrup, J., Novak, I. and Grosell, M. (2003) Sodium and chloride transport in soft water and hard water acclimated zebrafish (Danio rerio). Biochim. Biophys. Acta, 1618(2): 207-218.

2. Craig, P.M., Wood, C.M. and McClelland, G.B. (2007) Gill membrane remodeling with soft-water acclimation in zebrafish (Danio rerio). Physiol. Genomics, 30(1): 53-60.

3. Engeszer, R.E., Patterson, L.B., Rao, A.A. and Parichy, D.M. (2007) Zebrafish in the wild: A review of natural history and new notes from the field. Zebrafish, 4(1): 21-40.

4. Spence, R. (2011) Zebrafish ecology and behaviour. In: Zebrafish Models in Neurobehavioral Research. p1-46.

5. Mills, D., Young, J. (1993) Aquarium Fish: Dorling Kindersley Pub. DK Handbooks, London.
6. Bilotta, J., Saszik, S., DeLorenzo, A.S. and Hardesty, H.R. (1999) Establishing and maintaining a low-cost zebrafish breeding and behavioral research facility. Behav. Res. Methods Instrum. Comput., 31(1): 178-184.

7. Spence, R., Ashton, R. and Smith, C. (2007) Oviposition decisions are mediated by spawning site quality in wild and domesticated zebrafish, Danio rerio. Behaviour, 144(8): 953-966.

8. Goolish, E.M., Evans, R., Okutake, K. and Max, R. (1998) Chamber volume requirements for reproduction of the zebrafish Danio rerio. Prog. Fish Cult., 60(2): 127-132.

9. Nasiadka, A. and Clark, M.D. (2012) Zebrafish breeding in the laboratory environment. ILAR J., 53(2): 161-168.

10. White, R.M., Sessa, A., Burke, C., Bowman, T., LeBlanc, J., Ceol, C., Bourque, C., Dovey, M., Goessling, W., Burns, C.E. and Zon, L.I. (2008) Transparent adult zebrafish as a tool for in vivo transplantation analysis. Cell Stem Cell, 2(2): 183-189.

11. Westerfield, M. (2000) The zebrafish book. A guide for the laboratory use of zebrafish (Danio rerio). $4^{\text {th }}$ ed., Univ. of Oregon Press, Eugene.

12. Darrow, K.O. and Harris, W.A. (2004) Characterization and development of courtship in zebrafish, Danio rerio. Zebrafish, 1(1): 40-45.

13. Spence, R., Gerlach, G., Lawrence, C., Smith, C. (2008) The behaviour and ecology of the zebrafish, Danio rerio. Biol. Rev. Camb. Philos. Soc., 83(1): 13-34.

14. Lieschke, G.J. and Currie, P.D. (2007) Animal models of human disease: Zebrafish swim into view. Nat. Rev. Genet., 8(5): 353-367.

15. Menke, A.L., Spitsbergen, J.M., Wolterbeek, A.P. and Woutersen, R.A. (2011) Normal anatomy and histology of the adult zebrafish. Toxicol. Pathol., 39(5): 759-775.

16. Wittmann, C., Reischl, M., Shah, A.H., Mikut, R., Liebel, U. and Grabher, C. (2012) Facilitating drug discovery: An automated high-content inflammation assay in zebrafish. $J$. Vis. Exp., 65: e4203.

17. Gemberling, M., Bailey, T.J., Hyde, D.R. and Poss, K.D. (2013) The zebrafish as a model for complex tissue regeneration. Trends Genet., 29(11): 611-620.

18. Nguyen, A.T., Koh, V., Spitsbergen, J.M. and Gong, Z. (2016) Development of a conditional liver tumor model by mifepristone-inducible Cre recombination to control oncogenic kras V12 expression in transgenic zebrafish. Sci. Rep., 6(1): $1-10$.

19. Nishimura, Y., Inoue, A., Sasagawa, S., Koiwa, J., Kawaguchi, K., Kawase, R., Maruyama, T., Kim, S. and Tanaka, T. (2016) Using zebrafish in systems toxicology for developmental toxicity testing. Congenit. Anom., 56(1): 18-27.

20. Amatruda, J.F., Shepard, J.L., Stern, H.M. and Zon, L.I. (2002) Zebrafish as a cancer model system. Cancer Cell, 1(3): 229-231.

21. Liu, S. and Leach, S.D. (2011) Zebrafish models for cancer. Annu. Rev. Pathol., 6: 71-93.

22. Etchin, J., Kanki, J.P., Look, A.T. (2011) Zebrafish as a model for the study of human cancer. Methods Cell Biol., 105: 309-337.

23. Topczewska, J.M., Postovit, L.M., Margaryan, N.V., Sam, A., Hess, A.R., Wheaton, W.W., Nickoloff, B.J., Topczewski, J. and Hendrix, M.J. (2006) Embryonic and tumorigenic pathways converge via Nodal signaling: Role in melanoma aggressiveness. Nat. Med., 12(8): 925-932.

24. Goldsmith, J.R. and Jobin, C. (2012) Think small: Zebrafish as a model system of human pathology. J. Biomed. Biotechnol., 2012: 817341.

25. Norton, W. and Bally-Cuif, L. (2010) Adult zebrafish as a model organism for behavioural genetics. BMC Neurosci., 11(1): 1-11.

26. Koehler, D. and Williams, F.E. (2018) Utilizing zebrafish and okadaic acid to study Alzheimer's disease. Neural Regen. Res., 13(9): 1538-1541. 
27. Xi, Y., Noble, S., and Ekker, M. (2011) Modeling neurodegeneration in zebrafish. Curr. Neurol. Neurosci. Rep., 11(3): 274-282.

28. Lieschke, G.J., Oates, A.C., Crowhurst, M.O., Ward, A.C. and Layton, J.E. (2001) Morphologic and functional characterization of granulocytes and macrophages in embryonic and adult zebrafish. Blood, 98(10): 3087-3096.

29. Sorribes, A., Porsteinsson, H., Arnardóttir, H., Jóhannesdóttir, I.H., Sigurgeirsson, B., De Polavieja, G.G. and Karlsson, K. (2013) The ontogeny of sleep-wake cycles in zebrafish: A comparison to humans. Front. Neural Circuits, 7: 178.

30. Jeong, J.Y., Kwon, H.B., Ahn, J.C., Kang, D., Kwon, S.H., Park, J.A. and Kim, K.W. (2008) Functional and developmental analysis of the blood-brain barrier in zebrafish. Brain Res. Bull., 75(5): 619-628.

31. Xie, J., Farage, E., Sugimoto, M. and Anand-Apte, B. (2010) A novel transgenic zebrafish model for blood-brain and blood-retinal barrier development. BMC Dev. Biol., 10(1): 1-14.

32. Watts, S.A., Powell, M., and D'Abramo, L.R. (2012) Fundamental approaches to the study of zebrafish nutrition. ILAR J., 53(2): 144-160.

33. Baraban, S.C. (2009) Zebrafish as a simple vertebrate organism for epilepsy research. In: Animal Models of Epilepsy. Humana Press, New Jersey, United States. p59-74.

34. Decui, L., Garbinato, C.L.L., Schneider, S.E., Mazon, S.C., Almeida, E.R., Aguiar, G.P.S., Müller, L.G., Oliveira, J.V. and Siebel, A.M. (2020) Micronized resveratrol shows promising effects in a seizure model in zebrafish and signalizes an important advance in epilepsy treatment. Epilepsy Res., 159: 106243.

35. Mazumder, A.G., Kumari, S. and Singh, D. (2019) Anticonvulsant action of a selective phosphatidylinositol-3-kinase inhibitor LY294002 in pentylenetetrazole-mediated convulsions in zebrafish. Epilepsy Res., 157: 106207.

36. Choo, B.K.M., Kundap, U.P., Bin Johan Arief, M.F., Kumari, Y., Yap, J.L., Wong, C.P., Othman, I. and Shaikh, M.F. (2019) Effect of newer anti-epileptic drugs (AEDs) on the cognitive status in pentylenetetrazol induced seizures in a zebrafish model. Prog. Neuropsychopharmacol. Biol. Psychiatry, 92: 483-493.

37. Choo, B.K.M., Kundap, U.P., Kumari, Y., Hue, S.M., Othman, I. and Shaikh, M.F. (2018) Orthosiphon stamineus leaf extract affects TNF- $\alpha$ and seizures in a zebrafish model. Front. Pharmacol., 9: 139.

38. Li, X., Liu, X., Li, T., Li, X., Feng, D., Kuang, X., Xu, J., Zhao, X., Sun, M., Chen, D. and Zhang, Z. (2017) $\mathrm{SiO}_{2}$ nanoparticles cause depression and anxiety-like behavior in adult zebrafish. $R S C A d v$., 7(5): 2953-2963.

39. Li, X., Ji, X., Wang, R., Zhao, J., Dang, J., Gao, Y. and Jin, M. (2020) Zebrafish behavioral phenomics employed for characterizing behavioral neurotoxicity caused by silica nanoparticles. Chemosphere, 240: 124937.

40. Cronin, A. and Grealy, M. (2017) Neuroprotective and neuro-restorative effects of minocycline and rasagiline in a zebrafish 6-hydroxydopamine model of Parkinson's disease. Neuroscience, 367: 34-46.

41. Flinn, L., Mortiboys, H., Volkmann, K., Köster, R.W., Ingham, P.W. and Bandmann, O. (2009) Complex I deficiency and dopaminergic neuronal cell loss in parkin-deficient zebrafish (Danio rerio). Brain, 132(6): 1613-1623.

42. Panula, P., Chen, Y.C., Priyadarshini, M., Kudo, H., Semenova, S., Sundvik, M. and Sallinen, V. (2010) The comparative neuroanatomy and neurochemistry of zebrafish CNS systems of relevance to human neuropsychiatric diseases. Neurobiol. Dis., 40(1): 46-57.

43. Piato, Â.L., Capiotti, K.M., Tamborski, A.R., Oses, J.P., Barcellos, L.J., Bogo, M.R., Lara, D.R., Vianna, M.R. and Bonan, C.D. (2011) Unpredictable chronic stress model in zebrafish (Danio rerio): Behavioral and physiological responses. Prog. Neuropsychopharmacol. Biol. Psychiatry,
35(2): 561-567.

44. Chakravarty, S., Reddy, B.R., Sudhakar, S.R., Saxena, S., Das, T., Meghah, V., Brahmendra Swamy, C.V., Kumar, A. and Idris, M.M. (2013) Chronic unpredictable stress (CUS)induced anxiety and related mood disorders in a zebrafish model: Altered brain proteome profile implicates mitochondrial dysfunction. PLoS One, 8(5): 63302.

45. Rambo, C.L., Mocelin, R., Marcon, M., Villanova, D., Koakoski, G., de Abreu, M.S., Oliveira, T.A., Barcellos, L.J., Piato, A.L. and Bonan, C.D. (2017) Gender differences in aggression and cortisol levels in zebrafish subjected to unpredictable chronic stress. Physiol. Behav., 171: 50-54.

46. Demin, K.A., Lakstygal, A.M., Chernysh, M.V., Krotova, N.A., Taranov, A.S., Ilyin, N.P., Seredinskaya, M.V., Tagawa, N., Savva, A.K., Mor, M.S. and Vasyutina, M.L. (2020) The zebrafish tail immobilization (ZTI) test as a new tool to assess stress-related behavior and a potential screen for drugs affecting despair-like states. J. Neurosci. Methods, 337: 108637.

47. Wei, P., Zhao, F., Zhang, X. and Ru, S. (2020) Long-term exposure of zebrafish to bisphenol S impairs stress function of hypothalamic-pituitary-interrenal axis and causes anxiety-like behavioral responses to novelty. Sci. Total Environ., 716: 137092.

48. Giacomini, A.C., Piassetta, A.S., Genario, R., Bonan, C.D., Piato, A., Barcellos, L.J. and de Abreu, M.S. (2020) Tryptophan alleviates neuroendocrine and behavioral responses to stress in zebrafish. Behav. Brain Res., 378: 112264

49. Sarasamma, S., Varikkodan, M.M., Liang, S.T., Lin, Y.C., Wang, W.P. and Hsiao, C.D. (2017) Zebrafish: A premier vertebrate model for biomedical research in Indian scenario. Zebrafish, 14(6): 589-605.

50. Javed, I., Peng, G., Xing, Y., Yu, T., Zhao, M., Kakinen, A., Faridi, A., Parish, C.L., Ding, F., Davis, T.P. and Ke, P.C. (2019) Inhibition of amyloid beta toxicity in zebrafish with a chaperone-gold nanoparticle dual strategy. Nat. Commun., 10(1): 1-14.

51. Richetti, S.K., Blank, M., Capiotti, K.M., Piato, A.L., Bogo, M.R., Vianna, M.R. and Bonan, C.D. (2011) Quercetin and rutin prevent scopolamine-induced memory impairment in zebrafish. Behav. Brain Res., 217(1): 10-15.

52. Yendapalli, P.R., David, D.C. and Balasundaram, A. (2019) Evaluating the combined cognitive enhancement effect of Brassica juncea and Cynodon dactylon extract in scopolamine induced amnesia zebrafish model. Toxicol. Environ. Health Sci., 11(3): 190-196.

53. Pullaguri, N., Nema, S., Bhargava, Y. and Bhargava, A. (2020) Triclosan alters adult zebrafish behavior and targets acetylcholinesterase activity and expression. Environ. Toxicol. Pharmacol., 75: 103311.

54. Nema, S. and Bhargava, Y. (2018) Quantitative assessment of cypermethrin induced behavioural and biochemical anomalies in adult zebrafish. Neurotoxicol. Teratol., 68: 57-65.

55. Nery, L.R., Eltz, N.S., Hackman, C., Fonseca, R., Altenhofen, S., Guerra, H.N., Freitas, V.M., Bonan, C.D. and Vianna, M.R.M. (2014) Brain intraventricular injection of amyloid- $\beta$ in zebrafish embryo impairs cognition and increases tau phosphorylation, effects reversed by lithium. PLoS One, 9(9): 105862.

56. Gao, D., Wu, M., Wang, C., Wang, Y. and Zuo, Z. (2015) Chronic exposure to low benzo [a] pyrene level causes neurodegenerative disease-like syndromes in zebrafish (Danio rerio). Aquat. Toxicol., 167: 200-208.

57. Das, S.K., Aparna, S. and Patri, M. (2020) Chronic waterborne exposure to benzo [a] pyrene induces locomotor dysfunction and development of neurodegenerative phenotypes in zebrafish. Neurosci. Lett., 716: 134646.

58. Wang, Y., Zhong, H., Wang, C., Gao, D., Zhou, Y. and Zuo, Z. (2016) Maternal exposure to the water soluble fraction of crude oil, lead and their mixture induces autism-like 
behavioral deficits in zebrafish (Danio rerio) larvae. Ecotoxicol. Environ. Saf., 134: 23-30.

59. Dwivedi, S., Medishetti, R., Rani, R., Sevilimedu, A., Kulkarni, P. and Yogeeswari, P. (2019) Larval zebrafish model for studying the effects of valproic acid on neurodevelopment: An approach towards modeling autism. $J$. Pharmacol. Toxicol. Methods, 95: 56-65.

60. Chen, J., Lei, L., Tian, L., Hou, F., Roper, C., Ge, X., Zhao, Y., Chen, Y., Dong, Q., Tanguay, R.L. and Huang, C. (2018) Developmental and behavioral alterations in zebrafish embryonically exposed to valproic acid (VPA): An aquatic model for autism. Neurotoxicol. Teratol., 66: 8-16.

61. Meshalkina, D.A., Kizlyk, M.N., Kysil, E.V., Collier, A.D., Echevarria, D.J., Abreu, M.S., Barcellos, L.J., Song, C., Warnick, J.E., Kyzar, E.J. and Kalueff, A.V. (2018) Zebrafish models of autism spectrum disorder. Exp. Neurol., 299(A): 207-216.

62. Gawel, K., Banono, N.S., Michalak, A. and Esguerra, C.V. (2019) A critical review of zebrafish schizophrenia models: Time for validation? Neurosci. Biobehav. Rev., 107: 6-22.

63. Barnhill, L.M., Murata, H. and Bronstein, J.M. (2020) Studying the pathophysiology of Parkinson's disease using zebrafish. Biomedicines, 8(7): 197.

64. Meshalkina, D.A., Kysil, E.V., Warnick, J.E., Demin, K.A. and Kalueff, A.V. (2017) Adult zebrafish in CNS disease modeling: A tank that's half-full, not half-empty, and still filling. Lab. Anim., 46(10): 378-387.

65. Stewart, A.M., Braubach, O., Spitsbergen, J., Gerlai, R. and Kalueff, A.V. (2014) Zebrafish models for translational neuroscience research: From tank to bedside. Trends Neurosci., 37(5): 264-278.

66. Kalueff, A.V., Stewart, A.M. and Gerlai, R. (2014) Zebrafish as an emerging model for studying complex brain disorders. Trends Pharmacol. Sci., 35(2): 63-75.

67. Stewart, A.M., Gerlai, R. and Kalueff, A.V. (2015) Developing highER-throughput zebrafish screens for in vivo CNS drug discovery. Front. Behav. Neurosci., 9: 14.

68. Machado, R.G. and Eames, B.F. (2017) Using zebrafish to test the genetic basis of human craniofacial diseases. $J$. Dent. Res., 96(11): 1192-1199.

69. Duncan, K.M., Mukherjee, K., Cornell, R.A. and Liao, E.C. (2017) Zebrafish models of orofacial clefts. Dev. Dyn., 246(11): 897-914.

70. Kanther, M., Scalici, A., Rashid, A., Miao, K., Van Deventer, E. and Fisher, S. (2019) Initiation and early growth of the skull vault in zebrafish. Mech. Dev., 160: 103578.

71. Keer, S., Cohen, K., May, C., Hu, Y., McMenamin, S. and Hernandez, L.P. (2019) Anatomical assessment of the adult skeleton of zebrafish reared under different thyroid hormone profiles. Anat. Rec., 302(10): 1754-1769.

72. Kague, E., Gallagher, M., Burke, S., Parsons, M., FranzOdendaal, T. and Fisher, S. (2012) Skeletogenic fate of zebrafish cranial and trunk neural crest. PLoS One, 7(11): e47394.

73. Mork, L. and Crump, G. (2015) Zebrafish craniofacial development: A Window into early patterning. Curr. Top. Dev. Biol., 115: 235-269.

74. Crucke, J. and Huysseune, A. (2015) Blocking VEGF signaling delays development of replacement teeth in zebrafish. J. Dent. Res., 94(1): 157-165.

75. McCarthy, N., Wetherill, L., Lovely, C.B., Swartz, M.E., Foroud, T.M. and Eberhart, J.K. (2013) PDGFRA protects against ethanol-induced craniofacial defects in a zebrafish model of FASD. Development, 140(15): 3254-3265.

76. Ellis, L.D., Soo, E.C., Achenbach, J.C., Morash, M.G. and Soanes, K.H. (2014) Use of the zebrafish larvae as a model to study cigarette smoke condensate toxicity. PLoS One, 9(12): 115305.

77. Massarsky, A., Jayasundara, N., Bailey, J.M., Oliveri, A.N., Levin, E.D., Prasad, G.L. and Di Giulio, R.T. (2015) Teratogenic, bioenergetic, and behavioral effects of exposure to total particulate matter on early development of zebrafish (Danio rerio) are not mimicked by nicotine. Neurotoxicol. Teratol., 51: 77-88.

78. Palpant, N.J., Hofsteen, P., Pabon, L., Reinecke, H. and Murry, C.E. (2015) Cardiac development in zebrafish and human embryonic stem cells is inhibited by exposure to tobacco cigarettes and E-cigarettes. PLoS One, 10(5): 0126259 .

79. Reynolds, K., Kumari, P., Sepulveda Rincon, L., Gu, R., Ji, Y., Kumar, S. and Zhou, C.J. (2019) Wnt signaling in orofacial clefts: Crosstalk, pathogenesis and models. Dis. Model Mech., 12(2): 037051.

80. Zhang, H., Yao, Y., Chen, Y., Yue, C., Chen, J., Tong, J., Jiang, Y. and Chen, T. (2016) Crosstalk between AhR and wnt/ $\beta$-catenin signal pathways in the cardiac developmental toxicity of PM2. 5 in zebrafish embryos. Toxicology, 355: $31-38$

81. Zhang, C., Frazier, J.M., Chen, H., Liu, Y., Lee, J.A. and Cole, G.J. (2014) Molecular and morphological changes in zebrafish following transient ethanol exposure during defined developmental stages. Neurotoxicol. Teratol., 44: 70-80.

82. Marrs, J.A., Clendenon, S.G., Ratcliffe, D.R., Fielding, S.M., Liu, Q. and Bosron, W.F. (2010) Zebrafish fetal alcohol syndrome model: Effects of ethanol are rescued by retinoic acid supplement. Alcohol, 44(7-8): 707-715.

83. Liu, Y. and Semina, E.V. (2012) pitx2 deficiency results in abnormal ocular and craniofacial development in zebrafish. PLoS One, 7(1): 30896.

84. Balow, S.A., Pierce, L.X., Zentner, G.E., Conrad, P.A., Davis, S., Sabaawy, H.E., McDermott B.M. Jr. and Scacheri, P.C. (2013) Knockdown of fbxl10/kdm2bb rescues chd7 morphant phenotype in a zebrafish model of CHARGE syndrome. Dev. Biol., 382(1): 57-69.

85. Jergensen, T., Cusmano, D. and Roy, N.M. (2019) Di-butyl phthalate (DBP) induces craniofacial defects during embryonic development in zebrafish. Ecotoxicology, 28(8): 995-1002.

86. Cedron, V.P., Weiner, A.M., Vera, M. and Sanchez, L. (2020) Acetaminophen affects the survivor, pigmentation and development of craniofacial structures in zebrafish (Danio rerio) embryos. Biochem. Pharmacol., 174: 113816.

87. Chiquet, B.T., Yuan, Q., Swindell, E.C., Maili, L., Plant, R., Dyke, J., Boyer, R., Teichgraeber, J.F., Greives, M.R., Mulliken, J.B. and Letra, A. (2018) Knockdown of Crispld2 in zebrafish identifies a novel network for nonsyndromic cleft lip with or without cleft palate candidate genes. Eur. J. Hum. Genet., 26(10): 1441-1450.

88. Küchler, E.C., Silva, L.A.D., Nelson-Filho, P., Sabóia, T.M., Rentschler, A.M., Granjeiro, J.M., Oliveira, D., Tannure, P.N., Silva, R.A.D., Antunes, L.S. and Tsang, M. (2018) Assessing the association between hypoxia during craniofacial development and oral clefts. J. Appl. Oral Sci., 26: e20170234.

89. Wang, H., Meng, Z., Liu, F., Zhou, L., Su, M., Meng, Y., Zhang, S., Liao, X., Cao, Z. and Lu, H. (2020) Characterization of boscalid-induced oxidative stress and neurodevelopmental toxicity in zebrafish embryos. Chemosphere, 238: 124753

90. Fushimi, S., Wada, N., Nohno, T., Tomita, M., Saijoh, K., Sunami, S. and Katsuyama, H. (2009) 17ß-Estradiol inhibits chondrogenesis in the skull development of zebrafish embryos. Aquat. Toxicol., 95(4): 292-298.

91. Makkar, H., Verma, S.K., Panda, P.K., Jha, E., Das, B., Mukherjee, K. and Suar, M. (2018) In vivo molecular toxicity profile of dental bioceramics in embryonic Zebrafish (Danio rerio). Chem. Res. Toxicol., 31(9): 914-923.

92. Rajendran, S., Annadurai, G. and Rajeshkumar, S. (2018) Characterization and toxicology evaluation of zirconium oxide nanoparticles on the embryonic development of zebrafish, Danio rerio. Drug Chem. Toxicol., 42(1): 104-111.

93. Zhang, Y., Zhang, Y., Zheng, X., Xu, R., He, H. and 
Duan, X. (2016) Grading and quantification of dental fluorosis in zebrafish larva. Arch. Oral Biol., 70: 16-23.

94. Zhao, L., Si, J., Wei, Y., Li, S., Jiang, Y., Zhou, R., Liu, B. and Zhang, H. (2018) Toxicity of porcelain-fused-to-metal substrate to zebrafish (Danio rerio) embryos and larvae.
Life Sci., 203: 66-71.

95. Huang, W., Wang, X., Zheng, S., Wu, R., Liu, C. and Wu, K. (2021) Effect of bisphenol A on craniofacial cartilage development in zebrafish (Danio rerio) embryos: A morphological study. Ecotoxicol. Environ. Saf., 212: 111991.

$* * * * * * * *$ 